\title{
O Interacionismo Simbólico e os estudos sobre cultura e poder*
}

Carlos A. Gadea

Resumo: Existe uma relação conceitual entre o Interacionismo Simbólico e os contemporâneos estudos sobre cultura e poder, o pós-estruturalismo e a denominada crítica pós-moderna. $O$ interesse é evidenciar em que medida assistimos a um gesto teórico e analítico que insere a problemática da política e do poder em claro nexo com os aspectos culturais e a ordem simbólica própria das interações sociais. Assim mesmo, o objetivo é sugerir que os heterogêneos Estudos Culturais, bem como a própria crítica pós-moderna se apresentam como uma espécie de reutilização de perspectivas interacionistas na sociologia na atualidade.

Palavras-chave: Interacionismo Simbólico, Cultura, Poder, Crítica Pós-moderna.

\section{I}

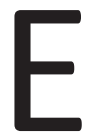
nquanto perspectiva de análise da realidade social, a história do Interacionismo Simbólico não se esgota, certamente, naquilo que foi considerado e definido por Herbert Blumer na década de 60 do século passado. A herança da denominada Escola de Chicago dos anos 1900 até 1950, e a influência diversa de autores como Thomas, Park, Wirth ou Hughes caracterizam o Interacionismo Simbólico como profundamente heterogêneo e de complexas raízes no cenário da teoria social. Nascido do desconforto com o funcionalismo e o estruturalismo predominantes na sociologia de meados do século $\mathrm{XX}$, foi protagonista de um percorrido semântico verdadeiramente rico e que, inclusive, parece ainda materializar-se em novas inquietações analíticas, empíricas e teóricas na atualidade. Metáforas sociológicas dos últimos vinte anos, como ser, "fragmentação social", heterogeneidade, "pluralidade do eu", "múltiplas realidades", dentre outras, apresentam-se como noções que parecem relembrar de estudos já clássicos como os do "pragmatismo filosófico" de William James (1961 [1907]), da psicologia social de George H. Mead (1982 [1934]), dos aportes de Alfred Schütz $(1932 ; 1962 ; 1974)$ e, inclusive, do brilhante "impressionismo sociológico" de Georg Simmel (1977 [1908]). Embora cunhado terminologicamente pelo próprio Blumer (1969), o Interacionismo Simbólico se compreende como uma perspectiva sobre teoria e método que tem na sua origem as primeiras interrogações formuladas na gênese da própria disciplina sociológica enquanto forma de entender a realidade social.
1. Professor e pesquisador do Programa de Pós-graduação em Ciências Sociais da Universidade do Vale do Rio dos Sinos, Unisinos, RS.

E-mail: cgadea@ unisinos.br

* Texto apresentado na Mesa Redonda Interacionismo Simbólico: Gênese, Desenvolvimento e Impacto na Sociologia Contemporânea, no XV Congresso Brasileiro de Sociologia, Curitiba, 26 a 29 de julho de 2011. 
2. Analogia que se pode estabelecer com o conceito de "províncias de significados", de William James (SCHÜTZ \& LUCKMANN, 1973).
Obviamente, desde as obras de Mead e Blumer até o nosso presente, muito tem mudado no mundo e, consequentemente, devem-se considerar as próprias mudanças no próprio debate acadêmico. Por isso, compreender um possível nexo entre os recentes estudos sobre cultura e poder com as perspectivas interacionistas na sociologia se apresenta como um desafio que merece sua atenção. De fato, considera-se que existe uma relação conceitual entre o Interacionismo Simbólico com os estudos sobre cultura e poder, o denominado pós-estruturalismo e a chamada crítica pós-moderna. Em segundo lugar, que essa espécie de reutilização do Interacionismo Simbólico, por parte dessas recentes perspectivas, está em sintonia com um redimensionamento da crítica, enquanto faceta pouco explorada ao interior do Interacionismo Simbólico e, isso último, objeto de detração por parte de alguns desavisados nostálgicos do estruturalismo. É possível, conseguintemente, considerar os estudos sobre cultura e poder, o pós-estruturalismo e a crítica pós-moderna, apesar das suas diferenças, eventuais desdobramentos do Interacionismo Simbólico? Será possível compreender essas recentes perspectivas como uma espécie de "politização do teórico", enquanto consideram as práticas sociais articuladas em torno do "cultural no político" e do "político no cultural"? Seria a partir dessa atitude que o Interacionismo Simbólico reintroduz a crítica ao interior das interações e "símbolos" que constituem "universos fechados de realidade"2?

II

Referindo-se ao contexto acadêmico dos anos 1980, Collins (2009 [1991]) afirmava que o "interacionismo simbólico, ao menos para alguns sociólogos, tem se tornado aliado da abordagem marxiana do conflito" (p. 223). De fato, certas facetas de uma determinada sociologia do conflito pareceram conectar dimensões estruturais do social com marcos de referência surgidos das próprias interações sociais, para assim poder compreender emergentes e concretas "situações de conflito". Assim, uma particular sociologia do conflito se materializou numa versão do marxismo que acusava a arbitrariedade da ordem social capitalista, sem negligenciar aqueles aspectos emanados da cultura vivida e da ação individual, tornando o Interacionismo Simbólico um aliado, sem dúvida, de grande interesse. Mas é também o próprio Collins (idem) quem manifestará que as lições deixadas pelas perspectivas interacionistas na sociologia teriam ocasionado "outro ramo" de seguidores que, em definitivo, procurariam "elaborar uma teoria científica geral sobre o self e sua relação com a estrutura social". Nessa perspectiva, "as instituições sociais (seriam) constituídas por papéis nos quais os indivíduos se (enquadrariam)" (idem), como ser pai, mãe, filho, estudante, vizinho, dentre outros. Resulta interessante perceber que esses "papéis não (seriam) negociados pelos participantes, (pois) já (existiriam) previamente" (idem), evidenciando-se um inquestionável vínculo com uma visão funcionalista 
sobre a sociedade. De todas as maneiras, a existência "prévia" dos papeis sociais, enquanto espécie de repertório cultural (SCHÜTZ, 1962), e a sua própria pluralidade, estariam sugerindo problematizar a relação entre a suposta espontaneidade e indeterminação da própria ação individual com a sua definitiva formalização em estruturas e instituições na sociedade, algo que situaria o debate clássico do Interacionismo Simbólico numa renovada vigência.

Enquanto Collins (idem) sugeriria uma saída a esse clássico impasse na recuperação do conceito de self de George $\mathrm{H}$. Mead, numa sorte de "teoria sociológica do pensamento", os estudos sobre cultura e poder, emergentes desde variadas tradições disciplinares e âmbitos da interação social (antropologia, psicologia social, teatro filosofia, performance, etc.), começariam a sugerir uma saída encontrada desde "o exterior" da tradição cientificista. Os interesses concretos desses novos estudos recairiam numa nova compreensão do que seria "cultura", identificando-a além do que seria, por exemplo, a arte, a literatura ou a música. A "cultura" passa a ser entendida como inerente de práticas e instituições da vida cotidiana, relacionadas à questão da política e do poder, como implícitas em relações de poder que, de fato, estabelecem certos limites aos processos simbólicos decorrentes dos significados da interação social. A "cultura", nessa perspectiva, é "experiência vivida", algo que indica um "modo de vida", historicamente contextualizado. Assim, a "cultura" não seria algo que se possui, no sentido de afirmar que Pedro "tem" cultura e João "não tem". Essa suposta "hierarquização" que supunha estabelecer limites entre o que seria "alta cultura" e a "cultura popular", por exemplo, deslegitima-se quando se admite que por "cultura" se deve entender "sensos comuns", espécie de "sistema central de práticas", sentidos e valores que, em absoluto, são algo abstrato, senão organizado e vivido, interpretado e representado. Nesse sentido, propiciou-se considerar de importância toda "produção de sentido", estendendo, dessa maneira, a noção de "cultura" à produção da própria realidade social e as suas contradições, conflitos e relações de poder.

Num sentido, e tal qual menciona Johnson (2004, p. 41-42), uma tendência nos novos estudos sobre cultura e poder insistirá entender a noção de "cultura" como algo a ser estudado como um todo e, in situ, localizado, em seu contexto material. Enfatiza-se a importância por desenvolver observações sobre a realidade que sejam capazes de apreender a "unidade ou a homologia das formas culturas e da vida material", que sejam capazes de recriar "experiências" socialmente localizadas. "Cultura" é, em definitivo, aquilo que entrelaça vida subjetiva com vida material e, em cujo entrelaçamento, se evidenciaria um "sistema central de práticas" sob a forma de implícitas relações de poder. Noutro sentido, "há aqueles que enfatizam uma independência relativa ou uma autonomia efetiva das formas e dos meios subjetivos de significação" (idem, p. 42). Trata-se 
3. Torna-se oportuno o esclarecimento realizado por Goffman (2006 [1975], p. 3): "El recurso crucial de James fue, desde luego, un juego bastante escandaloso con la palabra mundo (o realidad). Lo que él quería significar no era el mundo, sino el mundo actual de una determinada persona". de certos estudos sobre cultura e poder que privilegiam a análise da "construção discursiva de situações e de sujeitos", para assim deixar transparecer "os mecanismos pelos quais o significado é produzido na linguagem, na narrativa ou em outros tipos de sistemas de significação" (idem). Dessa maneira, enquanto a primeira tendência pareceu incorporar à noção de "vida material" os aspectos simbólicos da interação social, a segunda procurou fugir o máximo possível de uma observação das atividades simbólicas como decorrentes de uma mera "estrutura objetiva" da realidade.

Fora esses eventuais distanciamentos sobre a análise da "cultura", os estudos sobre cultura e poder protagonizariam uma visível aliança com o Interacionismo Simbólico, ao encontrar a sua especificidade na ordem do método, já que pareceriam se apresentar como antirreducionistas e antideterministas, operando desde um enfoque contextual na relação entre cultura e poder. O enfoque contextual aludido sugere que não é possível a existência de independência ou autonomia de uma prática social das forças do contexto que a constituem enquanto tal. Considerando que o contexto é um emaranhado e entrelaçamentos de relações específicas em que emerge uma prática social, esse enfoque contextual torna objeto de suas inquietações desvendar essas relações, opondo-se, dessa maneira, aos reducionismos epistemológicos que de antemão impõem uma dimensão concreta (economia, cultura, sociedade, discurso) como aquilo que se instituiu em princípio explicativo da realidade. Nesse sentido, nos estudos sobre cultura e poder, vislumbra-se uma estratégia de observação: a "cultura", compreendida como prática social, encontra-se numa sequencialidade de interações e símbolos que fazem parte de uma realidade social nomeada e classificada, em que as ações das pessoas e as classificações têm algum significado. Através da interação se experimenta a maneira de classificar o mundo ${ }^{3}$ e a maneira que se espera que o indivíduo se comporte nele: a capacidade de pensamento, por exemplo, parece estar moldada pela interação social, sendo através dela que as pessoas aprendem os significados e os símbolos que permitem atuar e interagir. Palavras mais, palavras menos, Herbert Blumer (1969), ao propor uma metodologia para o estudo da vida de grupo, diria que o meio de toda interação é, necessariamente, um meio definido simbolicamente, na medida em que as pessoas interpretam e definem as ações alheias, dando-lhe respostas baseadas nos significados que outorgam às mesmas. Foi situando a "cultura" no centro das atenções que, em definitivo, o Interacionismo Simbólico foi adquirindo dimensões renovadas nas preocupações dos recentes estudos sobre cultura e poder.

\section{III}

“Com a extensão do significado de cultura - de textos e representações para 
práticas vividas -, considera-se em foco toda produção de sentido" (ESCOSTEGUY, 2004, p. 143), embora, não necessariamente, para compreender-se o que significa "cultura" tenha que se exilar a dimensão textual e o representacional na produção do próprio sentido. De fato, como fazê-lo, se o sentido atribuído às "práticas vividas" está inserido em mecanismos de interpretação que emergem da linguagem e da ordem do discurso? Contrariamente, deve-se admitir que a compreensão de uma situação vivida é textual ${ }^{4}$, na medida em que esse conhecimento não está integrado só de conceitos, mas sim de palavras, e que essas palavras podem sugerir múltiplos significados ${ }^{5}$.

Isso leva a considerar que a "linguagem" e as conjunturais "regras da cultura" não são derivadas, necessariamente, de "estruturas sociais subjacentes" ou de "sistemas de significados estáveis", senão de interações sociais em que as pessoas definem as situações vividas, atribuindo-lhes nomes e significados. Mas isso não estaria supondo que as "variáveis estruturais", tais como classe, status e poder, estejam sendo negligenciadas por essa perspectiva textual da leitura da realidade social? Em absoluto se trata de negligenciar aspectos considerados "importantes" para a análise da realidade. Torna-se imprescindível recordar que as variáveis classe, status e poder não significam nada em si mesmas, já que, como categorias explicativas do social, não possuem significados universalmente válidos. Por seu caráter abstrato, não são mais do que representações derivadas de um tipo de ordenamento do mundo. Um modelo sociológico que torna essas categorias como um "dado" objetivo da realidade, e cujas atividades e produções culturais sejam lidas como expressões de "posições" de classe, status ou poder (ou de gênero, raça, etc.), revela-se, fundamentalmente, determinista e teoricamente ingênua. As variáveis classe, status e poder se materializam, cabalmente, numa teoria do poder e da realidade social que interage em campos de experiências sociais e culturais, linguísticas e históricas que se apresentam só ligadas a uma "idéia de estrutura"6, e não a uma "objetiva" estrutura social determinada. É a forma da relação social que atribui o caráter interpretativo às próprias categorias (classe, status e poder) advindas de um suposto "sistema de significados estável"7. Assim, considerar a "forma da relação" de importância no contexto da análise sobre a cultura e o poder é percebê-la, em última instância, não necessariamente emanada de uma teoria do poder construída sobre bases estruturalistas. Não se pode perder de vista que, aparentemente, em toda ação individual "sabe-se" que um si mesmo (MEAD, 1982 [1934]) está presente na interpretação de uma situação vivida tal qual um texto a ser desvendado.

Esta atenção para uma dimensão estendida do significado de "cultura" permite um "giro hermenêutico" só possível dentro dos limites da má reputação que tem a análise da realidade social. Trata-se de uma virada fenomenológica subversiva, em que o importante de uma situação vivida é a "sensação de
4. A "textualidade" consiste em indicar como significa um texto e não o que significa; compreender que um texto está integrado por palavras que podem ter distintos significados. "Texto" no sentido semiológico de discurso extenso, ou seja, de "todas" as práticas de interpretação, que incluem a linguagem, mas que não se limitam a ela. Ver Derrida (2008 [1967]).

5. Contra a noção essencialista da certeza de sentido, apela-se ao conceito central do estruturalismo: o sentido não é inerente aos signos nem àquilo referido, senão que resulta das relações entre eles. A consequência pós-estruturalista desse argumento, em termos derrideanos, relaciona-se a considerar as estruturas de sentido incluindo e implicando o observador. Nesse sentido, afirma-se que "observar é interagir". Isso não supõe, como muitos podem pensar, que existe um rechaço à "razão" como fonte explicativa da realidade, mas sim à representação dogmática sobre si mesma como certeza atemporal. Igualmente, não supõe admitir que, consequentemente, nada, de fato, seja "real", já que tudo se limitaria a uma 
construção cultural, linguística ou histórica, mas sim em admitir que nada é menos real por ser cultural, linguístico ou histórico, sobre todo se não existe "uma realidade universal" ou atemporal contra a qual se possa comparar. Como manifesta Derrida, isso não significa dizer, tão simplesmente, que existe um número infinito de sentidos, senão que significa dizer que "nunca há um só" sentido (DERRIDA, 2008 [1967]).

6. No sentido de um a priori sobre o social que permite às pessoas definirem um-mundoem-comum-com as outras pessoas. Se, por motivos explicativos, a "ideia de estrutura" a que se faz menção se associa, de certa forma, com a "ideia de ordem" extraída da tradição pragmática, pode-se considerar a "teoria bergsoniana das ordens concorrentes" como uma analogia válida. A "ideia de estrutura" se assemelha a um tipo particular de ordem que se espera ver e com respeito ao qual toda outra ordem se apresenta como um ordenamento contingente (SCHÜTZ, 1962, p. 270).

7. De forma análoga, pode-se considerar a "polivalência tática dos discursos" a que se refere Foucault $(1988$, p. 122), seu ser real" (JAMES, 1961 [1907]) e, fundamentalmente, os seus desdobramentos acerca de uma estrutura do conhecimento que sugere um marco binário de ordenamento do mundo (masculino-feminino, branco-negro, sul-norte, inclusão-exclusão, etc.). Acontece que o gesto por "conhecer" a partir desse marco binário de ordenamento do mundo não pode sugerir, como questão central, um instrumental conceitual que a prioristicamente não assuma seu caráter contingente. Não se trata de outra coisa do que tornar visível como as formas diversas de "determinismo sociológico" podem, ainda, tornar-se armadilhas difíceis de contornar em momentos de confrontar interação social com as tensões próprias dos sub-universos da cultura e do poder. Pode resultar curioso que foi o próprio Herbert Blumer (1969), herdeiro do pragmatismo a la William James (1961 [1907]) e dos enfoques interacionistas de George H. Mead (1982 [1934]), quem se dedicou, em extensas linhas, a tentar "afastar-se" desse "determinismo sociológico" que não admitia que as sociedades humanas estejam compostas de indivíduos dotados de si mesmos. Contrariamente, veriam as pessoas como simples organismos com certo tipo de organização que respondem às "forças" que atuam sobre elas. Ditas forças estariam incluídas na "estrutura da sociedade", como é o status, o papel social, os costumes, as instituições, a representação coletiva, os valores e as normas. A suposição consiste em admitir que a conduta das pessoas, enquanto membros de uma sociedade, é a simples expressão da influência que sobre elas exercem ditas forças (BLUMER, 1969).

A crítica a essas perspectivas desenvolvida por Blumer está em sintonia com a possibilidade de pretender explicar o entorno social e cultural a partir de conceitos "relacionais", sem ignorar-se um olhar arquetípico de toda uma tradição sociológica que adquire forma em George Simmel (1977 [1908]). O que está praticamente explícito no Interacionismo Simbólico é uma concepção da realidade que pressupõe que "todos nós somos fragmentos" e, então, que o conhecimento que adquirimos é necessariamente fragmentário, no seio de situações vividas. Tanto Simmel como as perspectivas interacionistas parecem partir de um princípio quase regulador da realidade social, em que "tudo interage com tudo", em que o que existem são permanentes relações de movimentos. Assim, os conceitos como "estrutura social" e "instituição social" desempenham papeis secundários, já que a sociedade não parece ser uma entidade completamente fechada em si mesma, absoluta, uma simples totalidade. Comparada com a interação entre as partes que a compõem, é só seu resultado. A sociologia, então, não tem nada a ver com uma noção reificada da sociedade, mas sim com a interação social e as formas de sociabilidade consequentes.

Trata-se, em consequência, de uma perspectiva analítica, e sobre a própria realidade social, que se preocupa por aquilo que pode ser vital para um indivíduo num momento determinado, implicando a "presença" do "outro". Seja na 
preocupação simmeliana nos modernos processos de individualização e diferenciação social, como na ênfase metodológica de Blumer sobre os significados dos "símbolos" decorrentes da relação social, trata-se de uma perspectiva em que a "lógica situacional" (THOMAS, 2005 [1923]) de qualquer relação ou interação adquire dimensão precisa. Essa perspectiva situacional pode ser muito próxima ao que Goffman (2006 [1975], p. 10) se refere com os "marcos de referência" que se encontram disponíveis para os indivíduos na sociedade, "marcos" que são básicos para a compreensão e explicação do sentido dos acontecimentos. Não obstante, e tal qual o próprio Goffman adverte, na maioria das "situações" sociais acontece uma multiplicidade de coisas diferentes de maneira simultânea. A caracterização do mesmo acontecimento pode ser diferente entre as pessoas envolvidas, ao depender do papel desempenhado numa tarefa que pode the proporcionar um julgamento de valores específico e diferente à de outra pessoa. Uma "situação", entendida também como uma maneira de organização da experiência, se relaciona não só com um indivíduo que isoladamente outorga significados a um acontecimento, senão também a um repertório cultural (SCHÜTZ, 1962) que, apesar de possibilitar um consenso aparente sobre o que estaria acontecendo nesse momento, traz consigo o questionamento que estabelece a base analítica do Interacionismo Simbólico: que os "símbolos" decorrentes de toda interação social não são universais nem objetivos; que os significados são individuais e subjetivos, no sentido de que é o próprio receptor quem os "outorga" aos símbolos de acordo com a maneira em que os "interpreta". Algo assim como considerar que quando os papéis que participam numa determinada situação são diferentes, muito provavelmente a visão que tem uma pessoa do que está acontecendo é bastante diferente da de outra pessoa.

No entanto, apresenta-se, em toda situação vivida, uma atitude por aceitar certas limitações epistemológicas daquilo concernente à ordem da linguagem e do discurso, do "dito", assim como do "marco de referências" da qual surge e, fundamentalmente, dos "condicionantes" sociais e institucionais que permitem aquela situação vivida em contextos concretos. Uma "ordem simbólica" decorrente da própria interação com os outros emerge na forma de um sistema de significações sociais pré-existentes. Nesse sentido, o indivíduo "compreende" que também ele está inserido em formas institucionais históricas (a família, o patriarcado, etc.), tornando-o um sujeito em absoluto ingênuo naquele ordenamento do mundo. Assim, todo indivíduo apareceria "conduzido" a partir de um exterior, perdendo-se a eventual autonomia de todo pensamento sobre aquela situação vivida. Estaria, consequentemente, em questionamento aquele si mesmo que cada indivíduo experimenta tal qual um texto a ser desvendado? Frente a esse impasse analítico, chega-se a estabelecer um "giro hermenêutico" de vital importância para a perspectiva do Interacionismo Simbólico, para a sua teoria subjetivista do significado e para a argumentando que “(...) no hay que imaginar un universo del discurso dividido entre el discurso aceptado y el discurso excluido o entre el discurso dominante y el dominado, sino como una multiplicidad de elementos discursivos que pueden actuar en estrategias diferentes". 
sua prioridade de entender o meio de toda interação como, necessariamente, um meio definido simbolicamente: trata-se de um "giro" decorrente da eventual aproximação epistêmica e analítica com os denominados Estudos Culturais e as preocupações da denominada crítica pós-moderna sobre a cultura e o poder.

\section{IV}

Talvez não se trate, de fato, de uma aproximação do Interacionismo Simbólico aos Estudos Culturais e às perspectivas mais recentes sobre a crítica pós-moderna. Talvez, contrariamente, se trate de um gesto que procura "dar forma" aos estudos sobre a cultura e à episteme pós-moderna a partir de uma reutilização das perspectivas teóricas e analíticas advindas do Interacionismo Simbólico e, de certa maneira, da própria pragmática da realidade social que a nutre. Daquele $s i$ mesmo eventualmente ferido ou inviabilizado, para o possível desvendamento da situação vivida, surge uma virada analítica em que aspectos que ligam cultura e poder se tornam incontornáveis. Fora as possibilidades que o Interacionismo Simbólico sugere enquanto espaço para a análise desse mundo vivenciado por um indivíduo quando "se vê condicionado" por um a priori da realidade social, por um mundo que precede a "seu estar nele", apresenta-se fundamental um olhar que permita compreender em que consiste esse espaço analítico que considera o mundo relacional inserido em complexas redes de relações de poder, instituições de saber e formas de articulação política.

A respeito, proeminentes críticas emergiram no contexto dos eventuais "desvios" que o Interacionismo Simbólico teria experimentado. Apesar de considerar que suas premissas podem ser até úteis como guia para o trabalho de campo, enfatiza-se a sua insuficiência na hora da elaboração teórica (GONZÁLEZ DE LA FE, 2003). Por isso, afirma-se que

(...) favorecidos por la moda de la integración conceptual de los años 80, se realizaron intentos de síntesis del Interaccionismo Simbólico blumeriano con prácticamente todas las microsociologías y enfoques teóricos y metateóricos: la teoría del intercambio, la fenomenología y la etnometodología, los estudios culturales y literarios de los semióticos posestructuralistas y posmodernos, la teoría feminista o las aportaciones de Goffman. (idem, p. 210)

Essa "síntese" teria ocasionado certa perda de identidade para o interacionismo de Blumer, ao desdobrar-se, aparentemente, em enfoques que o reduziram às questões básicas das ciências sociais. A apontada "fragmentação" decorrente da sua fragilidade nos anos 1980, assim como os intercâmbios epistemológicos 
e conceituais com o denominado "giro pós-moderno" teria gerado, na opinião de alguns, que o Interacionismo Simbólico se dissolvesse no mosaico policromo e caótico da sociologia do fim do século (idem, p. 211). Na verdade, essa sentença, inserida num compêndio de diversas conjeturas, fez parte de um inconfundível gesto, de parte de muitos intelectuais, por materializar uma atitude militante contra enfoques que reintroduziram a "questão pós"8 no debate acadêmico dos anos 1990, logo após do evidente desgaste e dispersão das temáticas vinculadas à globalização (GADEA, 2007).

Um exemplo sintomático desse gesto pode estar nas apreciações formuladas por Reynoso (2000), ao destacar as tímidas tentativas que alguns intelectuais empreenderam para fusionar os elementos analíticos próprios do Interacionismo Simbólico com os dos chamados Estudos Culturais. Compilações como as realizadas por Becker \& McCall nos anos 1990, sob o sugestivo título de Symbolic Interaction and Cultural Studies, possibilitaram o exercício de uma crítica férrea por parte de Reynoso. Na sua perspectiva, a compilação não era mais do que

(...) una cantidad de ensayos sin casi ningún tipo de marca política o pragmática, (mencionando) a los estudios (culturais) solamente en el prólogo en el cual aparece esa definición tortuosa y equivocada (...). Ninguno de los diez autores que luego hacen uso de la palabra se detuvo a averiguar en qué consisten los estudios culturales, ni mencionan una sola idea característica de los mismos (...). (p. 200)

No entanto, o problema mais evidente dessa compilação não recairia nessa "ausência" dos temas representativos dos denominados Estudos Culturais, mas sim naquilo que Mattelart \& Neveu (2004) diagnosticam quando caracterizam as consequências da "internacionalização e da crise dos Estudos Culturais": a sua despolitização. A compilação referida, a exemplo das tentativas por uma fusão do Interacionismo Simbólico com os Estudos Culturais, evidencia o que arquetipicamente representou, para muitos, o encontro dos Estudos Culturais com o pós-estruturalismo e a crítica pós-moderna. Nessa preocupação, e na atualização do Interacionismo Simbólico,

(...) hay algo de política, elaborada como si se estuviera conteniendo el asco, y como si lo político estuviera restringido apenas al ejercicio de una crítica contra no se sabe qué, con la que siempre se amaga pero que nunca se materializa. (REYNOSO, 2000, p. 200)

"A evolução dos estudos culturais desde os anos 1980 não pode ser dissociada de um processo de despolitização", admitem Mattelart \& Neveu
8. Em alusão concreta à diversa nomenclatura recorrente para caracterizar fenômenos políticos, culturais e filosóficos, por exemplo, a pósvanguarda, o pósestruturalismo, o pós-industrialismo, o pós-modernismo, etc. 
9. Para complementar, Reynoso (2000, p. 146) dirá: "Una vez dentro de esta estrategia, el estudiante puede pasar toda su carrera debatiendo interpretaciones, desarrollando lecturas más matizadas y provocativas, descubriendo nuevos textos marginados y significados no advertidos antes, sin encontrar, en todo su camino, a ningún miembro de la audiencia que le pregunte si alguna de esas cosas tiene algún interés para la vida de alguien".
(2004, p. 152-153), algo semelhante ao diagnóstico que Reynoso (2000) realiza quando analisa a suposta aproximação do Interacionismo Simbólico com as preocupações analíticas dos Estudos Culturais.

O "afastamento" de muitas das pesquisas recentes da "vontade de unir questões existenciais e desafios científicos" (atitude própria daquela "nova esquerda" que tinha dado origem aos Cultural Studies na Grã-Bretanha) reflete o argumento central da crítica ao desinteresse com a política e ao descompromisso com as questões ligadas a um trabalho acadêmico crítico. Com o desaparecimento dos "pais fundadores", os Estudos Culturais se apresentariam órfãos da militância (MATTELART \& NEVEU, 2004, p. 153). Não obstante, seria o seu processo de legitimação e institucionalização o que, ao reduzir a marginalidade de seus pesquisadores, e abrir a possibilidade de ocupar espaços acadêmicos importantes, teria condenado os Estudos Culturais a um simples "giro lúdico", "excesso de estilo", "celebração do artifício", "evasão da responsabilidade social" e a um "afastamento da realidade" (REYNOSO, 2000, p. 146) 9

Talvez tenham sido pouco condescendentes os argumentos de Reynoso e Mattelart \& Neveu com o espaço acadêmico e intelectual ocupado pelos Estudos Culturais mais recentes e os desdobramentos analíticos protagonizados pelo Interacionismo Simbólico. Por um lado, considera-se "el movimiento intaraccionista (como) ser una de las prácticas más inclinadas al idealismo y más prolijamente consonantes con el pensamiento de la derecha neoliberal norteamericana" (REYNOSO, 2000, p. 201). Ao mesmo tempo, que a "penetração" do pós-modernismo nos Estudos Culturais provocou a perda dos referentes clássicos dos estudos que ligaram cultura com política e poder, supondo que a episteme pós-moderna se reduz a um "giro literário" e a "metáforas textualistas" (ibidem, p. 145). Em outro sentido, admite-se que os Estudos Culturais atuais teriam "pactuado" seu desenvolvimento com o liberalismo econômico e o conservadorismo político triunfante dos anos 1980 e 1990, seduzidos pelas

(...) lógicas econômicas de rentabilidade em curto prazo (que) adquirem um peso crescente até no funcionamento das instituições e editoras universitárias, no acesso ao espaço midiático. Em tais condições, o sucesso do teoricismo, a solicitação de conceitos e de autores dotados do impressionante poder de 'relativizar' e de 'desconstruir' tudo, a fascinação pelos simulacros (...), a redução do mundo social a um caleidoscópio de textos e de discursos exprimem um humor intelectual cujo sentido é profundamente político. (MATTELART \& NEVEU, 2004, p. 157-158)

Mas, seria possível admitir, sem ressalvas, essa associação do movimento 
interacionista com um determinado pensamento político de direita? E reduzir a influência da crítica pós-moderna e do pós-estruturalismo sobre os Estudos Culturais a um mero "giro literário"? De início, e no campo das possibilidades da interpretação, pode-se perceber, ao menos, a manifestação de certos incômodos de uma geração de intelectuais um tanto "presa" a uma sociologia crítica que lê a cultura e o poder sob o halo dos ensinamentos da clássica "crítica negativa" da Escola de Frankfurt e de uma pontual teoria crítica da sociedade ${ }^{10}$.

Tanto no trabalho de Reynoso como no de Mattelart \& Neveu existe pouca discussão "ao interior" dos próprios Estudos Culturais e do Interacionismo Simbólico. $\mathrm{O}$ de Mattelart \& Neveu se apresenta como um interessante relato do nascimento e das posteriores vicissitudes dos Estudos Culturais, desde sua gênese na Grã Bretanha até a sua posterior migração ao contexto acadêmico latinoamericano e aos denominados Latin-American Studies. Embora existam reflexões acerca das suas influências teóricas e das suas preocupações, evidencia-se como um projeto disciplinar e político que teria sucumbido a seu próprio peso na academia. Por sua parte, Reynoso optou por realizar uma crítica aos Estudos Culturais desde a produção acadêmica de diversos intelectuais, criticando seus postulados, advertindo as nuances pouco estimulantes ao beber do pós-modernismo e do pós-estruturalismo, e inclusive se lamentando do escasso êxito da sua suposta aliança com o Interacionismo Simbólico. Não obstante, ainda permanece em aberto a possibilidade de espaços analíticos que considerem o mundo relacional inserido em relações de poder, instituições de saber e formas de articulação política. Reynoso, por exemplo, parece apelar a uma espécie de pós-marxismo aliado a uma clara desconfiança com toda uma tradição sociológica crítica do estruturalismo. Apresenta observações muito próximas de "desabafos" cientes de uma estratégia por desmistificar, a partir de algumas obras selecionadas, as contribuições tanto dos Estudos Culturais como do Interacionismo Simbólico. Fora a qualidade ou não daquilo que foi produzido na tentativa por fusionar Interacionismo Simbólico com os Estudos Culturais, e a estes com a crítica pós-moderna e o pós-estruturalismo, há uma forma que o social assume enquanto espaço a ser pensado que, sem dúvida, diz respeito a um interessante "giro hermenêutico". Dessa forma, é possível considerar o Interacionismo Simbólico e aos estudos sobre cultura e poder perspectivas de análise que negligenciam assuntos ligados ao poder e à política?

\section{V}

Nas diversas interações sociais, e na leitura "desconstrutiva" de qualquer situação e contexto onde se vê inserido, o indivíduo "parece descobrir" que aquilo que existe e que se autoproclama como "verdadeiro" não passa de ser uma mera "figura da linguagem"; mas que tem "o poder" de inseri-lo em uma complexa rede de relações sociais. Certas "regras da cultura" se materializam
10. "O que em definitivo parece evidenciar-se no intelectual crítico é uma vocação moralista e disciplinadora própria de quem se atribui a capacidade de decidir sobre o que é correto e o que não é. (...) 0 que em definitivo parece materializar a posição política e acadêmica de um intelectual crítico é a de uma espécie de guardião da metaestabilidade da crítica. (...) $\mathrm{Na}$ atualidade, um intelectual crítico insistirá em convencer a todos sobre 'a verdade dos acontecimentos'. Tentará explicar que, por trás do imediato e intransitivo, existem estruturas, forças, poderes que determinam os fenômenos. As 'estruturas objetivas do mundo' são as que devem desvelar-se, o que exigiria uma sensibilidade e posição política que tem tomado consciência do seu lugar (...)" (GADEA, 2007, p. 196). 
nesse mundo de significações realizadas por aqueles que entram em relação, já que quando "alguém fala" e, em definitivo, entra "no mundo", não é só ele quem o faz, e sim o "marco de referências" disponibilizado para uma situação específica e aquilo que se tem denominado como o "outro generalizado" (MEAD, 1982 [1934]). Nesta cena, o individuo parece exercer certa "capacidade" de questionar e desestabilizar, com seu pensamento e "posição", "regras da cultura" conjunturalmente expostas como sendo o mundo a ser/estar sendo vivido e desvendado, possibilitando considerar que a "cultura", nesse sentido, deixa de ser representada com a "ingenuidade" que muitos a supõem. Ela "se apresenta" nas interações sociais, tal qual começou a entender-se desde a tradição sociológica simmeliana e da Escola de Chicago. Sendo assim, o "giro hermenêutico" aludido toma como valor inestimável dirigir a atenção para alguns aspectos críticos na "produção de cultura", no sentido de entendê-la como própria de uma realidade social nomeada e classificada em que as ações das pessoas têm algum significado.

E que significados são esses que estabelecem uma presumível forma de articulação política? Que interação, simbolicamente mediada, é aquela entre o indivíduo e o seu contexto, traduzível num universo fechado de realidade? Quando Blumer (1969) admitia que os enfoques classicamente considerados sociológicos supunham que as ações das pessoas seriam o resultado de forças particulares que as produziriam, ironicamente sentenciava que, nesse sentido, não haveria nenhuma necessidade por se preocupar pelo significado dessas ações. Paulatinamente, com as teorizações foucaultianas, percebeu-se que, nas situações em que são constituídas (e se constituem) as relações sociais, se evidenciam formas particulares de "opressão" estreitamente ligadas às maneiras de como se atribuem os significados às ações empreendidas. Se bem no Interacionismo Simbólico aparece pouco clara a importância que supostamente teria a análise das formas de inscrição, através das quais as pessoas são representadas, seria com a virada pós-estruturalista que a análise das interações sociais assumiria como de grande importância a temática do poder, da cultura e da sua representação. Diferentes situações sociais permitiriam que múltiplas relações de poder entrassem em jogo, sem esquecer, inclusive, que nessas diferentes situações acontece uma multiplicidade de coisas diferentes de maneira simultânea (GOFFMAN, 2006). Assim, a articulação política derivada dos significados atribuídos a qualquer situação vivida se vincula com tornar evidente, de maneira crítica, uma específica "forma da relação" que, antes de tudo, pretende colocar entre parênteses o marco binário de um ordenamento do mundo (sobre gênero, raça, sexualidade, dentre outros) que estabelece hierarquias culturais e históricas concretas.

Tal qual uma simples metáfora, as múltiplas interrogantes que um indivíduo 
se pode formular, o seu "instável" si mesmo e a "figura da linguagem" constitutiva da realidade do seu mundo, permitem estabelecer uma relação conceitual entre o Interacionismo Simbólico e os estudos sobre cultura e poder. Quando um indivíduo "reflete" a partir do "dito" pelo outro numa específica interação social, introduz questões sobre o saber e a sua institucionalização, sobre política e poder, que pareceria "desdobrar" aquilo que foi próprio da ideia de sociedade e indivíduo das perspectivas interacionistas na sociologia. A mediação simbólica de toda interação social é reconsiderada à luz das preocupações que desde o pós-estruturalismo e a crítica pós-moderna vem se colocando há bastante tempo. Assim, enterram-se sentenças como as que consideram o Interacionismo Simbólico como "una teoria enfáticamente micro, una ortodoxia ancestral e inelástica, que contemplaba los 'significados' como algo que surge de cada negociación ocasional entre iguales" (REYNOSO, 2000, p. 201). O "giro hermenêutico" que os Estudos Culturais e a crítica pós-moderna protagonizam sob os auspícios do Interacionismo Simbólico evidenciam que a aproximação analítica que experimentam não denota "despolitização", nem desinteresse pelos assuntos ligados ao poder e à política. Muito pelo contrário, o poder e a política entram num processo de ressemantização interessante, abandonando uma imagem que a tem "colonizado" através de uma particular teoria crítica. Ressemantização da crítica como principal tarefa deste "giro hermenêutico": trata-se de questionar a defesa do papel do intelectual crítico tradicional, ao autoconsiderar-se que só desde a perspectiva universalizadora do intelectual, dos valores que elabora (éticos, estéticos, epistemológicos) e representa, é possível formular uma perspectiva crítica sobre as "ilusões da ideologia dominante" e "o poder" subjacente em toda relação social. Por outro lado, é o amplo espaço dos estudos sobre cultura e poder uma prática intelectual que supõe uma finalidade política que assume o horizonte da utopia como a sua materialização? Os recentes estudos sobre cultura e poder devem estar submersos numa concreta teleologia, na medida em que se assume um a priori sobre o mundo a ser superado? Não se trataria, em todo caso, de um projeto acadêmico e intelectual que questionaria tais posicionamentos políticos e intelectuais? Não se trata, aqui, e é importante esclarecer, de uma suposta defesa de um projeto acadêmico e da sua institucionalização, mas sim de uma espécie de reterritorialização da figura da "crítica" e do intelectual ligada, isso sim, à tradição do Interacionismo Simbólico, os Estudos Culturais, o pós-estruturalismo e a crítica pós-moderna.

Há um interesse por "ampliar" o espectro analítico da interação simbólica, quando se consideram as relações sociais em absoluto vazias (ou esvaziadas) de componentes políticos, estéticos ou epistemológicos. A tarefa "desconstrutiva" se torna inseparável de uma perspectiva analítica que observa os significados das interações simbolicamente mediadas inseridas em incontornáveis nexos entre cultura e poder. Contrariamente ao que alguns consideram, o 
"giro pós-moderno" não só trouxe a ironia como estratégia expressiva para uma crítica ao universo da modernidade, senão que estabeleceu a possibilidade de problematizar aquilo que não aparecia, tão visivelmente, nas perspectivas interacionistas. Por isso, a partir do pragmatismo filosófico, a crítica pós-moderna parece se visualizar em uma espécie de reutilização daqueles elementos analíticos que tinham sido negligenciados pela hegemonia de perspectivas mais enraizadas no determinismo estrutural. No Interacionismo Simbólico, na fenomenologia de Schütz, nos estudos sobre cultura e em toda a tradição sociológica que considera o social próprio daquilo que se constitui "em relação" radica, em grande maneira, o suporte teórico que a crítica pós-moderna estabelece ao se referir à desestabilização ou decomposição dos "grandes relatos explicativos da realidade" (LYOTARD, 1989 [1979]). Não há muita novidade a respeito: quando a importância à "lógica situacional" das ações e aos seus significados, aos fragmentos e à fluidez, e à pluralidade de mundos (ou as "múltiplas realidades"), materializa-se nos contemporâneos estudos sobre cultura e poder, é possível considerar que se torna claro o fio condutor que entrelaça preocupações análogas entre as perspectivas interacionistas, os Estudos Culturais e a crítica pós-moderna. Esse é o "giro hermenêutico" que, "ao interior" das perspectivas interacionistas, permite compreender que o indivíduo "se apresenta" como um significante que traduz uma "ordem simbólica" decorrente de toda interação social e, por consequência, fazendo parte de relações de poder.

Abstract: There is a conceptual relationship between the Simbolic Interacionism and the contemporary studies about culture and power, the post- structuralism and the so called post-modern critique. The interest is to show the extent to which we witness an analytical and theoretical gesture that inserts the politic and power problematic in contact with the cultural aspects and the symbolic order of the social interactions. Even so, the main objective is to suggest that the heterogeneous Cultural Studies, as well as the post-modern critique, present themselves as a kind of reuse of interacionist perspectives in the current sociology.

Keywords: Simbolic Interacionism, Culture, Power, Post-modern Critique.

Referências

BLUMER, Herbert. Simbolic Interactionism. New Jersey: Ed. Prentice-Hall, 1969.

COLLINS, Randall. Quatro tradiçoes sociológicas. Petrópolis: Ed. Vozes, 2009 [1991]. 
DERRIDA, Jaques. Gramatologia. São Paulo: Ed. Perspectiva, 2008[1967].

ESCOSTEGUY, Ana Carolina. "Estudos Culturais: uma introdução". In: SILVA, Tomaz Tadeu da (Org.), O que é, afinal, Estudos Culturais?, Belo Horizonte: Ed. Autêntica, 2004.

FOUCAULT, Michel. Microfísica del poder. Madrid: Ed. La Piqueta, 1992 [1979]

3, México, 1988.

"El sujeto y el poder". Revista Mexicana de Sociología, UNAM, N

GADEA, Carlos A. Paisagens da Pós-modernidade. Cultura, Política e Sociabilidade na América Latina. Itajaí: Ed. Univali, 2007.

GOFFMAN, Erving. Frame Analysis. Los marcos de la experiencia. Madrid: Ed. Centro de Investigaciones Sociológicas, 2006 [1975]

GONZÁLEZ DE LA FÉ, Teresa. "El Interaccionismo Simbólico". In: Salvador Giner (Org.), Teoría Sociológica Moderna. Barcelona: Ed. Ariel, 2003.

HALL, Stuart. Da diáspora. Identidades e mediações culturais. Belo Horizonte: Ed. Ufmg, 2003.

JAMES, William. Pragmatismo. Buenos Aires: Ed. Aguilar, 1961 [1907].

JOHNSON, Richard. "O qué é, afinal, Estudos Culturais? In: Silva, Tomaz Tadeu da (Org.), O que é, afinal, Estudos Culturais?. Belo Horizonte: Ed. Autêntica, 2004.

LYOTARD, Jean François. La condición postmoderna, Madrid: Ed. Cátedra, 1989 [1979].

MATTELART, Armand \& NEVEU, Érik. Introdução aos estudos culturais. São Paulo: Ed. Parábola, 2004.

MEAD, George H. Espíritu, persona y sociedad. Desde el punto de vista del conductismo social. Buenos Aires: Ed. Paidós, 1982 [1934].

REYNOSO, Carlos. Apogeo y decadencia de los estudios culturales. Barcelona: Ed. Gedisa, 2000.

SCHÜTZ, Alfred \& LUCKMANN, Thomas. Las estructuras del mundo de la vida. Ed. Amorrortu, Buenos Aires, 1973.

SCHÜTZ, Alfred. El problema de la realidad social. Ed. Amorrortu, Buenos Aires, 1962.

SIMMEL, Georg. Sociologia. Madrid: Ed. Revista de Occidente, 1977 [1908].

THOMAS, William I. "La definición de la situación". In: Cuadernos de Información y comunicación, n. 10, s/l, 2005, [1923]. 